\title{
(ه) Contemporary radiosurgery of cerebral cavernous malformations: Part 1. Treatment outcome for critically located hemorrhagic lesions
}

\author{
Gábor Nagy, MD, PhD, ${ }^{1}$ Wendy Burkitt, BSc, ${ }^{3}$ Stuart S. Stokes, MBChB, ${ }^{2}$ \\ Debapriya Bhattacharyya, MBBS, FRCS, ${ }^{2-4}$ John Yianni, MD, FRCS, ${ }^{2-4}$ \\ Jeremy G. Rowe, DM, FRCS, ${ }^{2-4}$ Andras A. Kemeny, MD, FRCS, ${ }^{4}$ and \\ Matthias W. R. Radatz, MD, FRCS ${ }^{2-4}$ \\ ${ }^{1}$ National Institute of Clinical Neurosciences, Budapest, Hungary; ${ }^{2}$ Department of Neurosurgery, and ${ }^{3}$ National Centre for \\ Stereotactic Radiosurgery, Royal Hallamshire Hospital; and ${ }^{\top}$ Thornbury Radiosurgery Centre, Sheffield, United Kingdom
}

OBJECTIVE Long-term benefits of radiosurgery (RS) applying modern protocols to treat cavernous malformations (CMs) remain unclear as critics may consider the decrease in the rebleed rate generally observed 2 years after RS as a reflection of the lesion's natural history. The authors adopted an early intention-to-treat attitude since rehemorrhage from deep-seated CMs ultimately leads to stepwise neurological deterioration. The safety of this early policy was previously demonstrated. Here, the authors revisit their current practice in a larger population with a longer follow-up time to assess the long-term effects of RS in the context of current knowledge on the natural history of CMs.

METHODS The authors conducted a retrospective analysis of 210 patients with 210 hemorrhagic CMs located in the brainstem, thalamus, or basal ganglia and treated with Gamma Knife RS between 1995 and 2014. Two hundred six patients had available follow-up, which was a median of 5.5 years (range 1-20 years). The median age was 37 years (0.5-77 years) at presentation and 43 (2-78) at treatment. One hundred twenty-seven CMs had bled once and 83 had had multiple hemorrhages prior to treatment.

RESULTS The lifetime annual bleed rate of CMs having a single hemorrhage prior to treatment was $2.4 \%$ per lesion. The hemorrhage rate stabilized at $1.1 \%$ after a temporary increase of $4.3 \%$ within the first 2 years after RS. The annual pretreatment hemorrhage rate was $2.8 \%$ for the lesions having multiple bleeds prior to RS with a pretreatment rebleed rate of $20.7 \%$ and with a modest gradual decrease within the first 5 years and remaining stable at $11.55 \%$ thereafter. The rebleed rate fell to $7.9 \%$ for the first 2 years after RS and declined further to $1.3 \%$ thereafter, which was significantly lower than the long-term pretreatment rebleed risk. The rate of hemorrhage-free survival remained $86.4 \%$ and $75.1 \%$ (1 patient each) at 20 years after RS in the single- and multiple-bleed groups, respectively.

Pretreatment hemorrhages resulted in permanent deficits in $48.8 \%$ of the cases with a single bleed and in $77.1 \%$ of the cases with multiple bleeds. Both the rate and severity of deficits were significantly lower in the first group. Only mild and a low rate of permanent neurological deficits were caused either by posttreatment hemorrhages $(7.4 \%)$ or by radiation $(7.2 \%)$. The rate of persistent morbidity in the single-bleed group remained significantly lower at the end of the study than pretreatment morbidity in the multiple-bleed group (OR 2.9, 95\% Cl 1.6-5.3). Lesion-specific mortality was $<1 \%$.

CONCLUSIONS The hemorrhage rate of CMs after RS remained low after the first 2 years during the longer follow-up period. The benefit of early treatment appears to be confirmed by the study results as repeated hemorrhages carry the risk of significantly higher cumulative morbidity than the morbidity associated with RS.

https://thejns.org/doi/abs/10.3171/2017.5.JNS17776

KEYWORDS cavernous malformation; radiosurgery; brainstem; thalamus; basal ganglia; hemorrhage; vascular disorders; stereotactic radiosurgery

ABBREVIATIONS ARE = adverse radiation effect; $\mathrm{AVM}=$ arteriovenous malformation; $\mathrm{CM}=$ cavernous malformation; $\mathrm{mRS}=$ modified Rankin Scale; $\mathrm{RHH}=\mathrm{Royal}$ Hallamshire Hospital; RS = radiosurgery; TRC = Thornbury Radiosurgery Centre.

SUBMITTED March 27, 2017. ACCEPTED May 30, 2017.

INCLUDE WHEN CITING Published online July 27, 2018; DOI: 10.3171/2017.5.JNS17776. 
$\mathrm{D}$ ESPITE increasing numbers of publications with positive results ${ }^{27}$ and our better understanding of the natural history of cerebral cavernous malformations (CMs), ${ }^{13,16,38}$ the role of radiosurgery (RS) in the management of these lesions remains controversia ${ }^{14}$ given the heterogeneity of available data and the lack of quality evidence..$^{33}$ Radiosurgery was introduced for the treatment of CMs based on the assumption that their pathological vessels would have a post-RS obliterative response similar to that of arteriovenous malformations (AVMs). ${ }^{21,37}$ However, unlike for AVMs, there is no radiological endpoint for RS of CMs; therefore, arguments for the use of RS rely solely on patient statistics. ${ }^{27}$ Therefore, most centers generally follow the original cautious policy of recommending RS only for surgically inaccessible CMs with repeated hemorrhages. ${ }^{20}$ Our policy has been intuitively more proactive from the beginning, treating CMs even after their first hemorrhage. If left untreated, repeated hemorrhages can lead to stepwise neurological deterioration especially from deep-seated lesions (located deep to the brainstem, thalamus, or basal ganglia); therefore, a minimally invasive treatment with low morbidity such as RS should have been considered even if the long-term benefits had yet to be confirmed. ${ }^{28}$ When reviewing our practice of treating deepseated CMs up to 2008, we, like other authors, ${ }^{15,18}$ found RS to be not only safe but also apparently effective, dramatically reducing annual rebleed rates after a latency period of 2 years. ${ }^{29}$ These results reassured us to continue our proactive practice, ${ }^{28}$ which has also been adopted by others. ${ }^{3,23,32}$
Since the publication of that earlier report, ${ }^{29}$ several studies have provided data confirming the reproducibility of good outcomes after contemporary CM RS. ${ }^{27}$ Thus, the most important remaining question is whether the clinical course of CMs following RS is truly better than their natural history. Given that several good-quality natural history studies with large patient cohorts have recently been published, ${ }^{16,24,38}$ we believed it would be worthwhile to revisit our current practice in the context of recent knowledge. The number of deep-seated CMs treated with modern RS in Sheffield reached 236 by the end of 2014 with the longest follow-up of 20 years, allowing us to perform an in-depth analysis of the effect of different presentations on long-term outcome. The results of our analysis of 210 critically located hemorrhagic CMs are presented here.

\section{Methods \\ Patient Details}

Three hundred thirty-four patients harboring CMs were treated with RS between 1986 and 2014 in Sheffield at either of two RS centers, the National Centre for Stereotactic Radiosurgery at the Royal Hallamshire Hospital (RHH) and the Thornbury Radiosurgery Centre (TRC; Fig. 1). We excluded 15 patients treated during the early experimental phase due to poor treatment definition as treatment planning had been based only on CT scans. ${ }^{26}$ This left 345 lesions in the remaining 319 patients since 1995. Of these, we analyzed $210 \mathrm{CMs}$ located in the brain-

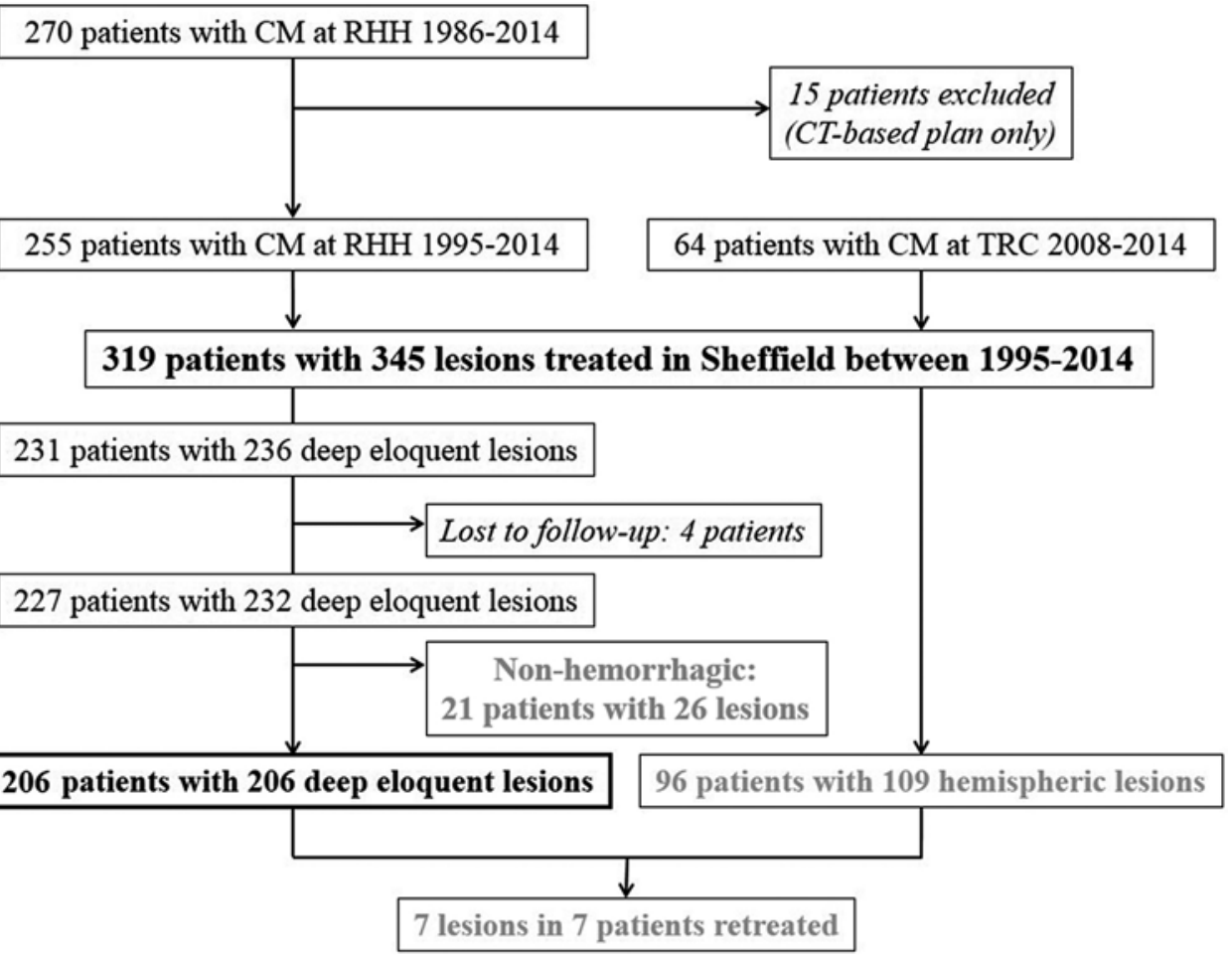

FIG. 1. Flowchart indicating the number of CMs and patients treated with RS at both centers in Sheffield. Two hundred ten patients with 210 lesions harboring deep-seated CMs were included in this study; 206 patients had available follow-up data (black). Twenty-one patients with 26 nonhemorrhagic CMs, 96 patients with 109 hemispheric/superficial CMs, ${ }^{30}$ and 7 lesions in 7 patients with repeat RS are subjects of separate analyses (gray). ${ }^{31}$ 
TABLE 1. Location and presentation of deep-seated CMs treated between 1995 and 2014 in Sheffield

\begin{tabular}{ccc}
\hline Parameter & No. & $\%$ \\
\hline Lesion location & & \\
Brainstem & 155 & 74 \\
Medullary & 16 & 10.3 \\
Pontomedullary & 18 & 11.6 \\
Pontine & 70 & 45.2 \\
Pontomesencephalic & 12 & 8 \\
Midbrain & 32 & 20.6 \\
Mesencephalo-thalamic & 7 & 4.5 \\
\hline Thalamus/basal ganglia & 55 & 26 \\
Thalamomesencephalic & 8 & 14.5 \\
Thalamic & 26 & 47 \\
Basal ganglia & 8 & 14.5 \\
Paraventricular & 6 & 11 \\
Internal capsule & 1 & 2 \\
Subinsular & 6 & 11 \\
\hline Presentation & & \\
\hline Brainstem & & \\
Single bleed & 91 & 59 \\
Multiple bleed & 64 & 41 \\
\hline Thalamic/basal ganglia & & \\
Single bleed & 36 & 65.5 \\
Multiple bleed & 19 & 34.5 \\
\hline
\end{tabular}

stem, thalamus, or basal ganglia in 210 patients who had presented with hemorrhage (Table 1), among which were 103 lesions in 103 patients who had been reported on in our earlier study with a shorter follow-up. ${ }^{29}$ Forty-two patients had multiple lesions, and hemispheric lesions in addition to the deep-seated CM were treated in 8 patients during the same session. There was a slight female preponderance $(54 \%)$ among the patients. The median age was 37 years (range $0.5-77$ years) at presentation and 43 (range 2-78) at treatment. One hundred twenty-seven CMs had bled only once and 83 had had multiple hemorrhages prior to treatment (Table 1). Before RS, 21 patients (10\%) underwent surgery-either clot evacuation, with or without partial resection, or shunt insertion.

\section{Treatment Details}

As an inclusion criterion for this study, stereotactic MRI had been used for localization and target definition. Our standard protocol is to perform T2-weighted and proton density imaging using 1.5-mm slices, TE $80 \mathrm{msec}, \mathrm{TR}$ $3000 \mathrm{msec}, 256$ matrix, number of signal averages 1. GammaPlan (Elekta AB) was used for dose planning. Treatments were delivered with the Gamma Knife model RBS 5000 (Nucletec) until 2001, Gamma Knife Model C (Elekta AB) until 2011, and Gamma Knife Perfexion (Elekta $\mathrm{AB}$ ) thereafter in the RHH and all with Perfexion in the TRC. The number of treated patients gradually increased from 3 in 1995 to an annual average of 20 more recently (Fig. 2A). The median time between presentation and treatment was 1 year (0.1-34 years). Cavernous malformations were defined within the hemosiderin ring and were treated after complete resolution of the last hematoma, and a median dose of 12-13 Gy (depending on location) was given to the $50 \%$ prescription isodose level, excluding coexisting developmental venous anomalies. ${ }^{27}$ Our standard treatment protocol has not changed essentially since 1995 , apart from a significant reduction in the prescription dose from 15 to 12 Gy after 2000 ( $\mathrm{p}<0.001$; Table 2).

\section{Follow-Up}

Treated patients are assessed primarily clinically in the referring neurosurgical unit, supplemented with reimaging as indicated. We recommend clinical follow-up in 6 months' time within the 1st year after RS and annually thereafter in an uneventful clinical course. As there is no radiological endpoint to demonstrate the effect of $\mathrm{RS}$, and without new symptoms there is no therapeutic reason for
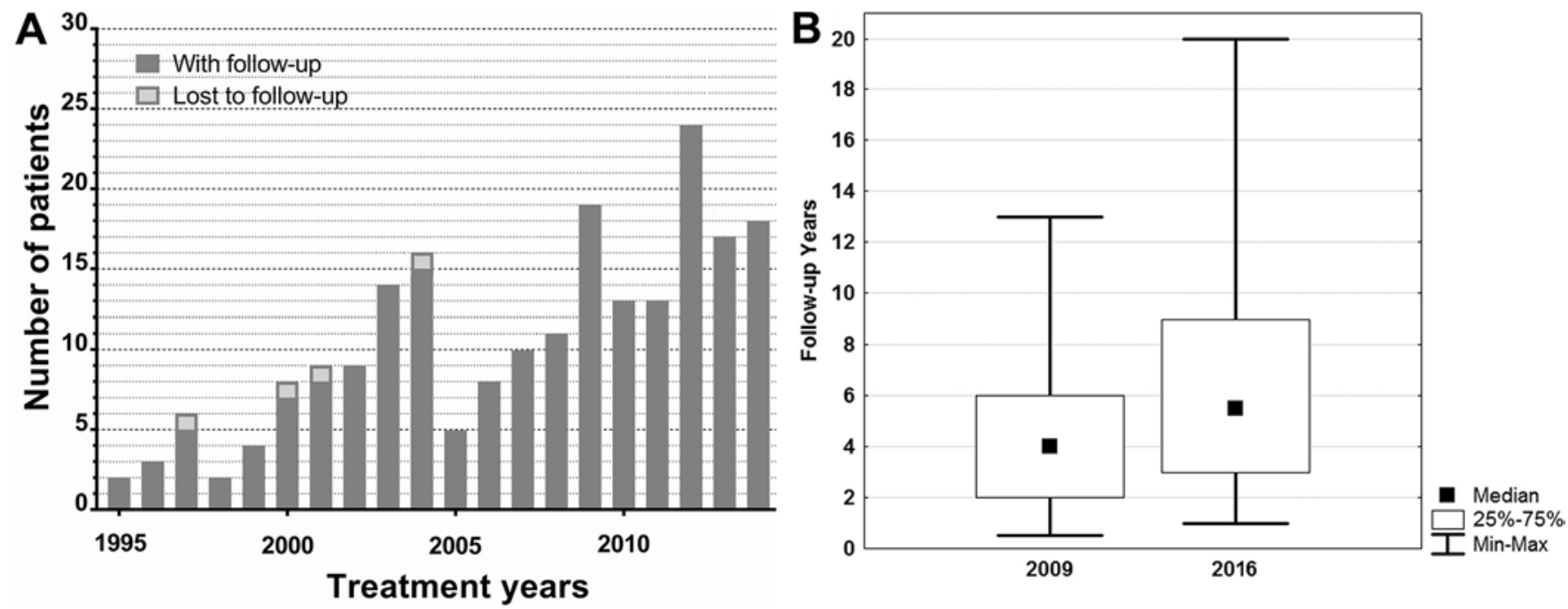

FIG. 2. A: Bar graph showing the number of patients treated each year. B: Follow-up times for our previous study ${ }^{29}$ (median 4 years, range 0.5-13 years; 99 patients) and our current study (median 5.5 years, range 1-20; 206 patients). 
TABLE 2. Summary of radiosurgical parameters

\begin{tabular}{|c|c|c|c|c|c|}
\hline \multirow[b]{3}{*}{ Parameter } & \multicolumn{5}{|c|}{ Median (range) } \\
\hline & \multicolumn{2}{|c|}{ Lesion Location } & \multicolumn{3}{|c|}{ Treatment Period } \\
\hline & Brainstem & Thalamus/BG & 1995-2000 & 2001-2009 & 2010-2014 \\
\hline $\mathrm{TV}\left(\mathrm{mm}^{3}\right)$ & $240 *(10-8400)$ & $537(3.5-5200)$ & $442 †(25-3142)$ & $303(22-8400)$ & $208(3.5-4470)$ \\
\hline $\mathrm{PIV}\left(\mathrm{mm}^{3}\right)$ & $260 \ddagger(11-6100)$ & $620(83-5000)$ & $503 \dagger(43-3800)$ & $372(11-6100)$ & $233(31-4810)$ \\
\hline Prescription isodose (\%) & $50(41-81)$ & $50(41-84)$ & $50(45-75)$ & $50(41-90)$ & $50(41-84)$ \\
\hline Prescription dose (Gy) & $12(10-18)$ & $13(12-20)$ & $15 \ddagger(10-20)$ & $12(10-17.5)$ & $12(11-16)$ \\
\hline Max dose (Gy) & $24(12-35.6)$ & $26(15.5-40)$ & $28 \ddagger(18-40)$ & $24(17.1-36.7)$ & $24(12-32)$ \\
\hline
\end{tabular}

BG = basal ganglia; $P I V=$ prescription isodose volume; $T V=$ target volume.

Treatment periods reflect on the utilization of developing equipment: Gamma Knife model RBS 5000, Model C, and Perfexion.

${ }^{*} p<0.01$.

$\dagger$ Not significant.

$\neq p<0.001$

imaging, we continue our earlier practice of recommending reimaging only in cases of clinically significant events. ${ }^{21,29}$ We updated our follow-up database in 2016 by contacting patients or general practitioners. In cases with clinically significant events reported, we requested detailed clinical information and scans from local hospitals. For deceased patients, information on the cause of death was obtained from either general practitioners or local hospitals. We obtained follow-up information for 206 patients (98\%) with a median follow-up of 5.5 years (range 1-20 years; Fig. 2).

\section{Definitions and Statistical Analysis}

"Symptomatic hemorrhage" is defined as a sudden neurological event with concurrent radiological evidence of a bleed. ${ }^{5}$ Rates of first hemorrhage were calculated based on the assumption of lesion presence since birth. ${ }^{27}$ Morbidity was assessed with the modified Rankin Scale (mRS). ${ }^{43}$ Scores were assigned by the first author based on reported neurological deficits and individual patient questionnaires addressing their daily activity. Both hemorrhage and morbidity rates were calculated for treated lesions, as opposed to patients. Any clinical deterioration after RS was investigated with reimaging to exclude hemorrhage. Events unrelated to hemorrhage were classified as transient adverse radiation effects (AREs) with perilesional edema developing within 12 months after treatment, permanent AREs developing typically more than 12 months after treatment, and transient neurological events without radiological evidence of perilesional edema (considered unrelated to treatment), as described previously. ${ }^{29}$ The Mann-Whitney U-test, Fish- er's exact two-sided test, and log-rank test were used for statistical comparisons, and the odds ratio or hazard ratio and $95 \%$ confidence intervals are given, as appropriate. A p value $<0.05$ was considered statistically significant.

No significant difference was found between the different treatment eras in terms of pretreatment and posttreatment hemorrhages or morbidity (data not shown). Likewise, the outcomes of the brainstem and thalamic/basal ganglia groups were not significantly different (data not shown) despite smaller brainstem lesions; therefore, we pooled data from these two subgroups.

\section{Results}

\section{Risk of Hemorrhage Before RS}

In the single-hemorrhage group, the annual pretreatment hemorrhage rate was $2.4 \%$. In the multiple-bleed group it was $2.8 \%$, and the rebleed rate was $20.7 \%$ before treatment (Table 3). Rates of the first bleed in the singleand multiple-bleed groups were not significantly different (OR 1.16, 95\% CI 0.88-1.54, $\mathrm{p}=0.31$ ). The median time between the presenting bleed and RS was 1 year (0.1-34 years) in the single-bleed group and 3 years (0.3-35 years) in the multiple-bleed group. The median time between the first and second bleed was 2 years ( $0.2-23$ years) in the latter group. The annual rebleed rate modestly decreased from $46.15 \%$ (95\% CI $34.8 \%-57.5 \%$ ) in the 1 st year to $32.15 \%$ (95\% CI $13.7 \%-50.6 \%$ ) in the 5 th year after the first bleed and thereafter remained $11.55 \%$ before RS (95\% CI 6.3\%-16.8\%; Fig. 3A).

TABLE 3. Annual hemorrhage rates before and after RS

\begin{tabular}{|c|c|c|c|c|}
\hline \multirow[b]{2}{*}{ Group } & \multicolumn{2}{|c|}{ Before RS } & \multicolumn{2}{|c|}{ After RS } \\
\hline & 1st Bleed & Rebleed & w/in 2 Years & After 2 Years \\
\hline Single-bleed & $\begin{array}{l}2.4 \%, 2.0-2.8 \\
125 \text { bleeds in } 5196 \text { lesion-yrs }\end{array}$ & - & $\begin{array}{l}4.3 \%, 1.7-6.9 \\
10 \text { bleeds in } 235 \text { lesion-yrs }\end{array}$ & $\begin{array}{l}1.1 \%, 0.2-2.0 \\
6 \text { bleeds in } 557 \text { lesion-yrs }\end{array}$ \\
\hline Multiple-bleed & $\begin{array}{l}2.8 \%, 2.2-3.4 \\
\quad 80 \text { bleeds in } 2891 \text { lesion-yrs }\end{array}$ & $\begin{array}{l}20.7 \%, 17.3-24.1 \\
113 \text { bleeds in } 547 \text { lesion-yrs }\end{array}$ & $\begin{array}{l}7.9 \%, 3.6-12.3 \\
12 \text { bleeds in } 151 \text { lesion-yrs }\end{array}$ & $\begin{array}{l}1.3 \%, 0.2-2.4 \\
5 \text { bleeds in } 381 \text { lesion-yrs }\end{array}$ \\
\hline
\end{tabular}

$-=$ not applicable

Values expressed as hemorrhage rate, $95 \% \mathrm{Cl}$, no. of bleeds in lesion-years. 

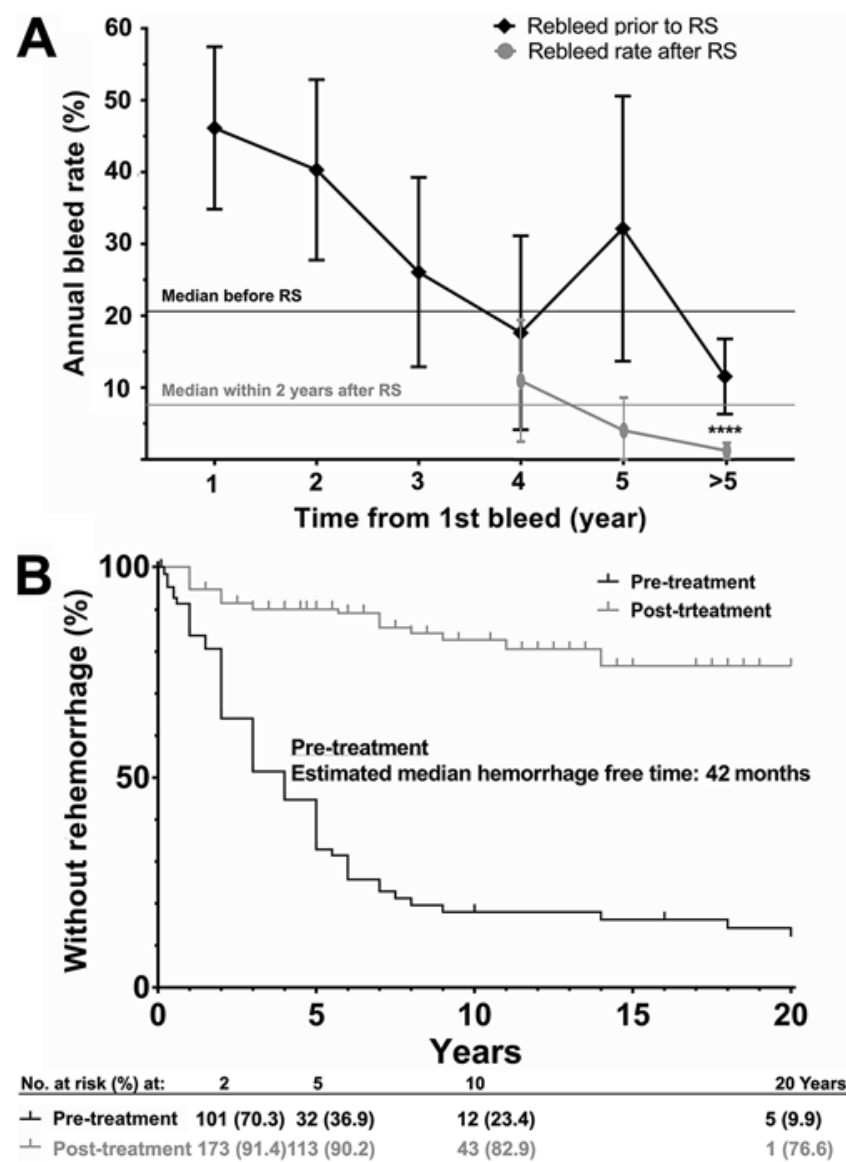

FIG. 3. A: Rebleed rates in the multiple-bleed group only modestly decreased within 5 years after the first bleed and remained $11.6 \%$ thereafter prior to RS (black). In contrast, within 2 years after RS, the rebleed rates in this group decreased to $1.3 \%$ (gray). B: Kaplan-Meier curves estimating hemorrhage-free survival of the pooled hemorrhagic group before ( $n=210$ patients, black) and after RS ( $n=206$ patients, gray). The difference was significant. ${ }^{* * *} p<0.0001$.

\section{Risk of Hemorrhage After RS}

In the single-bleed group, the rebleed rate was $4.3 \%$ within the first 2 years after RS, falling to $1.1 \%$ thereafter (Fig. 4 and Table 3); the risk of rebleeding after 2 years was significantly lower (OR 4.1, 95\% CI 1.4-11.1, p < 0.01). In the multiple-bleed group, the rebleed rate was $7.9 \%$ within the first 2 years after RS and fell to $1.3 \%$ thereafter; the risk of rebleeding after 2 years was significantly lower (OR 6.5, 95\% CI 2.3-16.8, $\mathrm{p}<0.001)$. Moreover, the longterm posttreatment rebleeding risk in the multiple-bleed group was significantly lower than the long-term rebleeding risk prior to treatment (OR 9.8, 95\% CI 3.6-24.6, $\mathrm{p}<$ 0.0001; Figs. 3A and 4).

The median hemorrhage-free survival time prior to treatment was estimated to be 42 months after hemorrhagic presentation, whereas $78 \%$ of the patients (1 patient) would remain hemorrhage free 20 years after RS (HR 5.54, 95\% CI 3.91-7.85, p < 0.0001; Fig. 3B). In the single- and multiple-bleed groups, $86.4 \%$ and $75.1 \%$ of patients (1 patient each), respectively, would remain hemorrhage free 20 years after RS (Fig. 5). The difference

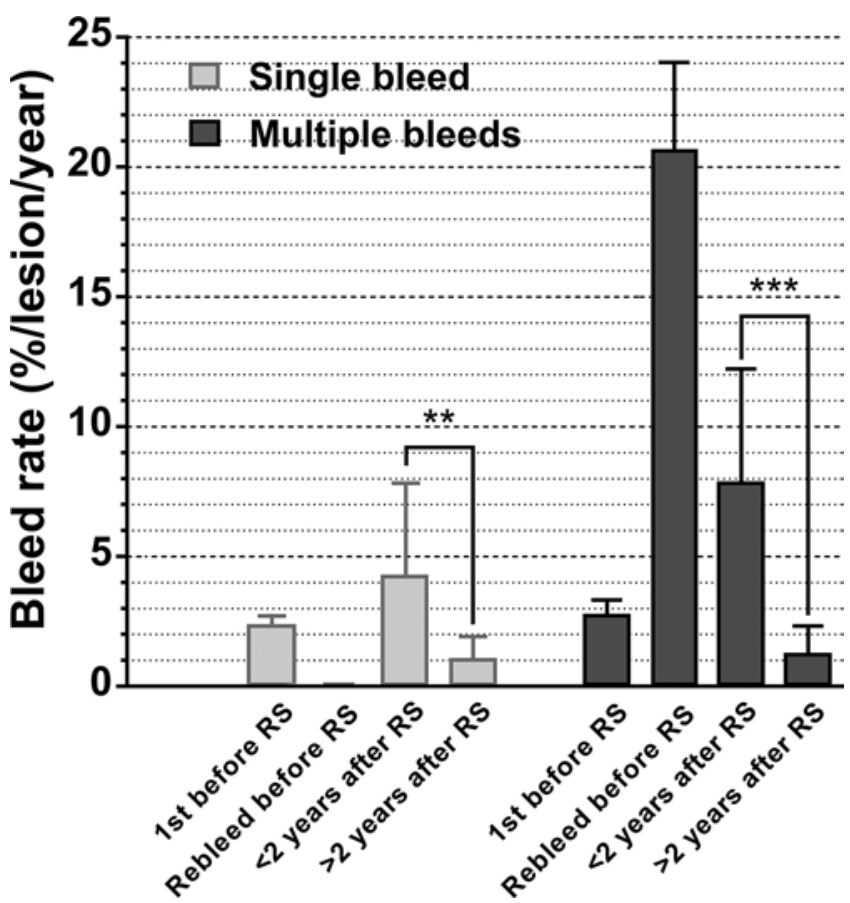

FIG. 4. Bar graph showing bleeding rates prior to and after RS. Error bars indicate the $95 \%$ confidence interval. ${ }^{* *} p<0.01 ;{ }^{* * *} p<0.001$.

in hemorrhage-free survival between the two groups was not significant.

Forty percent (95\% CI 3.0-76.9) of the pediatric group (10 patients, age $\leq 14$ years) and only $11.7 \%$ (95\% CI 7.2$16.3)$ of the adult population (196 patients) suffered from a bleed after RS (OR 5.0, 95\% CI 1.5-17.6, p < 0.05).

\section{Pretreatment Morbidity}

Before treatment, permanent neurological deficits occurred in $48.8 \%$ of cases (95\% CI 39.9-57.7) in the single-

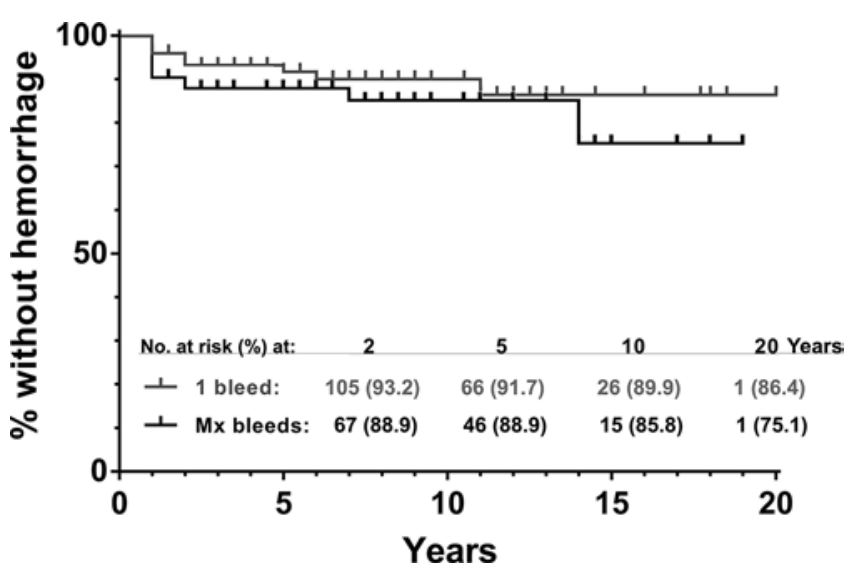

FIG. 5. Kaplan-Meier curves for hemorrhage-free survival after RS. The patients at risk and the percentage of hemorrhage-free survivals are given for each group at 2, 5, 10, and 20 years after RS. Gray line and text, single-bleed group; black line and text, multiple-bleed group (Mx bleeds). 


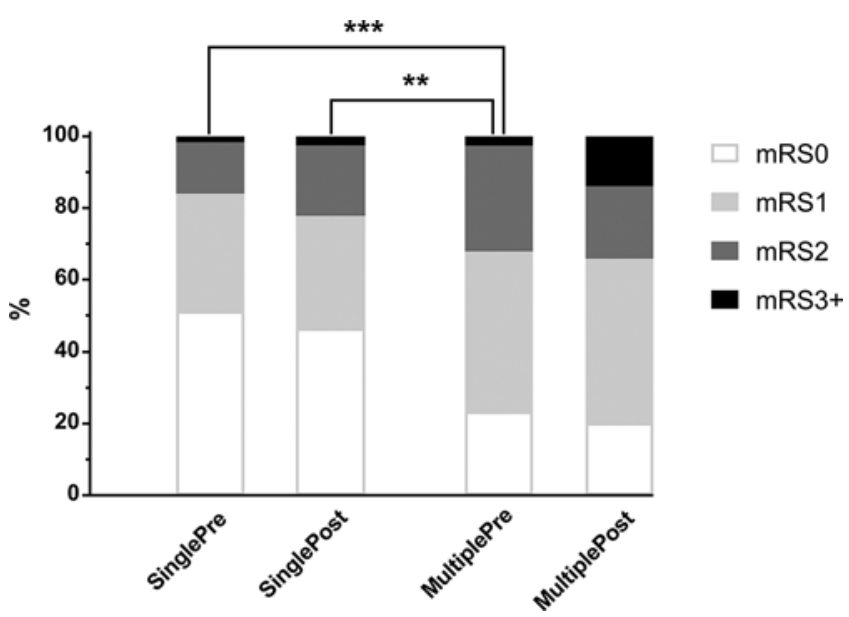

FIG. 6. Bar graph showing permanent morbidity before and after RS in patients with single ( $n=122$ patients) and multiple hemorrhages $(n=$ 79 patients). Overall permanent morbidity did not significantly change in the two groups, but the rate of score $3+$ morbidity was significantly increased after RS $(p<0.01)$. Persistent morbidity was significantly higher in the multiple-bleed group before RS than in the single-bleed group before and after RS. Post = persistent neurological deficit at the endpoint of posttreatment follow-up; Pre = morbidity before treatment. ${ }^{* *} p<0.01 ;{ }^{* * *} p<0.001$.

bleed group. The rate of permanent deficits was significantly higher in the multiple-bleed group at $77.1 \%$ (95\% CI 67.9-86.3; p < 0.001; Fig. 6 and Table 4). Repeated bleeds were associated with increased risks of new deficits (OR $3.4,95 \%$ CI $1.8-6.2, \mathrm{p}<0.001)$ and with more severe disabilities (mRS score $>1$; OR 2.5, 95\% CI 1.2-4.8, p <0.01).

\section{Posttreatment Morbidity}

Twenty-seven (13.1\%) of 206 lesions with follow-up bled 33 times after RS, and the chance of suffering from permanent disability after the bleed was $45.5 \%$ (15 of 33 bleeds; Table 4). Posttreatment hemorrhage-related morbidity was 7.4\% (95\% CI 3.8-11.1) for the whole cohort (5.9\% with an increase of $1 \mathrm{mRS}$ score and $1.5 \%$ with an increase of $2 \mathrm{mRS}$ scores). The rate of transient and permanent AREs was $8.3 \%$ (17/206) and 7.2\% (14/194 with 2-year follow-up; 95\% CI 3.5-10.9), respectively (all an increase of $1 \mathrm{mRS}$ score). Transient neurological events without radiological evidence of hemorrhage or perilesional edema occurred 12 times in 10 patients after RS. The rate of persistent neurological deficits was significantly lower in the single-bleed group after RS $(53.3 \%, 95 \%$ CI 44.7-62.6) than in the multiple-bleed group prior to RS $(77.1 \%$; $p<0.01$; Fig. 6). This refers to a significantly higher risk of permanent deficits in the multiple-bleed group prior to RS than the overall morbidity of the single-bleed group after RS (OR 2.9, 95\% CI $1.6-5.3, \mathrm{p}<0.001)$.

\section{Treatments After RS}

Five lesions were surgically removed after a post-RS bleed, and 6 lesions were treated with RS twice. This second group is the subject of another study addressing the results of multiple RS treatments. ${ }^{31}$
TABLE 4. Pre- and posttreatment $m R S$ scores in percentage of lesions having more than 1 year of follow-up

\begin{tabular}{|c|c|c|c|c|}
\hline \multirow[b]{2}{*}{ Group } & \multicolumn{4}{|c|}{ mRS Score } \\
\hline & 0 & 1 & 2 & $3-4$ \\
\hline \multicolumn{5}{|l|}{ Single-bleed $(n=125)$} \\
\hline Pre-RS mRS & 51 & 33 & 14.5 & 1.5 \\
\hline $\begin{array}{l}\text { Morbidity of posttreatment hemorrhage } \\
\quad(+\mathrm{mRS})\end{array}$ & 92.3 & 5.7 & 2 & 0 \\
\hline Morbidity of AREs (+mRS) & 94.3 & 5.7 & 0 & 0 \\
\hline Posttreatment end state (mRS) & 46.7 & 31.2 & 19.7 & 2.4 \\
\hline \multicolumn{5}{|l|}{ Multiple-bleed $(n=81)$} \\
\hline Pre-RS mRS & 24 & 45 & 28.5 & 2.5 \\
\hline $\begin{array}{l}\text { Morbidity of posttreatment hemorrhage } \\
(+\mathrm{mRS})\end{array}$ & 93 & 3.5 & 3.5 & 0 \\
\hline Morbidity of AREs (+mRS) & 90 & 10 & 0 & 0 \\
\hline Posttreatment end state (mRS) & 22 & 40.2 & 26.8 & 11 \\
\hline
\end{tabular}

Posttreatment morbidity is expressed as the percentage of lesions for which scores increased posttreatment to the mRS score shown (+mRS), and other values are expressed as the percentage of lesions for which the mRS score shown was obtained at the time of assessment.

\section{Mortality}

Six deaths occurred during the follow-up period. Four were unrelated to the treated $\mathrm{CM}$, and the cause of death was unknown in one case. One patient died of hemorrhage from one of her treated brainstem CMs. This gives an estimate of treatment-specific mortality of $0.49 \%-0.99 \%$.

\section{Discussion}

\section{Natural History of CMs}

Understanding the natural history of CMs is fundamental in therapeutic decision-making. However, as these lesions are rare and heterogeneous in terms of both presentation and location, ${ }^{13}$ substantial variability among earlier studies has often led to confusion. Recent developments focusing on standardization and data accumulation may bring us closer to consensus. First, it has become widely accepted that hemorrhage is considered as a clinical event of acute or subacute onset of symptoms with evidence of concurrent hemorrhage in order to avoid earlier confusion due to the presence of a hemosiderin ring even in asymptomatic cases. ${ }^{5}$ Second, despite evidence of de novo CM formation, both retrospective studies assuming lesion presence since birth and prospective studies have provided similar estimates $(1.4 \%-2.5 \%)$ for annual hemorrhage rates. ${ }^{13}$ Third, hemorrhagic presentation was found to be the most significant risk factor for further bleeding, indicating the destabilization of CMs by the first bleed. . $^{, 13,38}$ While the annual bleed rate was found to be $0.4 \%-0.6 \%$ after nonhemorrhagic presentation, ${ }^{13}$ the annual rebleed rate was estimated between $4.5 \%$ and $33.77 \%, 17,22$ giving rise to a cumulative rebleeding incidence of $16 \%-57 \%$ at 5 years and up to $72 \%$ at 10 years after hemorrhagic presentation., ${ }^{7,16}$ Last, a brainstem location was found to be a significant risk factor for rebleeding with an annual rebleed rate of $32.3 \%$ as compared to $6.3 \%$ for other lesion locations,${ }^{38}$ and the estimat- 
ed risk of a first hemorrhage within 5 years of diagnosis was $30.8 \%$ and $8 \%$ with or without hemorrhagic presentation, respectively. ${ }^{16}$ Another study found even lower 5-year hemorrhage-free survival with brainstem CMs, estimating $53 \%$ with median hemorrhage-free survival times of 5-6 and 9 years for cases of hemorrhagic and nonhemorrhagic presentation, respectively. ${ }^{24}$ Similarly, the annual rebleed rate of deep supratentorial CMs was found to be higher $(14.1 \%)$ with a $55.3 \%$ 5-year overall hemorrhage-free survival. ${ }^{39}$ The risk of morbidity due to a single bleed from a brainstem CM is also increased. Up to $40 \%-60 \%$ of cases are left with persistent morbidity, and the risk of death is also substantial. ${ }^{10,35}$ Moreover, each subsequent bleeding episode carries the chance of cumulatively increasing permanent disability. ${ }^{41}$ Pretreatment behavior of CMs in our study was consistent with these results.

Several studies have suggested that the elevated rebleed risk decreases a few years after the first hemorrhage ("temporal clustering"), a matter of intensive debate since its first description. ${ }^{7}$ In the original study, a 2.4-fold decline in the annual rebleed rate from $25.2 \%$ to $9.6 \%$ was found 2.5 years after hemorrhagic presentation. While such 1.65 - to 2.3-fold declines in the rebleed rate after 2 years have been confirmed by several subsequent observational studies, in all but one of these studies the rebleed rate did not return to baseline (defined as the annual rate of first hemorrhage) even 5 years after the first bleed. ${ }^{16,38}$

\section{Management Options for CMs}

Given CMs' relatively benign natural history and considerable risk with intervention, the role of the three management options - microsurgical removal, RS, and observation-in the treatment of deep-seated CMs is yet to be defined. ${ }^{33,34}$ For such lesions, surgical removal remains a salvage treatment generally recommended in only limited circumstances. ${ }^{2}$ Although the risk of microsurgery has decreased over the decades with increasing experience and safer techniques, ${ }^{2,42}$ it is still substantial, resulting in $10 \%-$ $14 \%$ persistent morbidity and $1.5 \%-1.9 \%$ mortality. ${ }^{11,12} \mathrm{Al}-$ though the procedure offers a definitive cure, the rate of complete resection is only $89 \%-91 \%$, and the rebleed rate never goes to zero: $62 \%$ of residual lesions rebleed with an annual rebleed rate of $0.5 \%-2 \%$ and mortality rate of $6 \% .^{11,12}$ The outcome of microsurgical resection is worse in the pediatric population, with $25 \%$ being left with persisting morbidity and $15 \%$ developing a recurrence with an annual rebleed rate of $5.25 \% .^{1}$ Thus, prophylactic surgical removal of deep-seated CMs in patients with no or minimal neurological deficit is not a common practice ${ }^{9}$ and remains an option only for those lesions that behave aggressively and are resectable with acceptable morbidity. From this perspective, we consider RS not as a competitive but as a complementary intervention since the question about these lesions is whether to observe them or to treat them with RS. Moreover, RS can also be an alternative intervention when surgery is technically feasible but medically contraindicated or declined by the patient. ${ }^{28}$

\section{Outcome After RS}

The first paper on modern CM RS was published in 1995 by the Pittsburgh group, ${ }^{21}$ who found a dramatic de- crease in the annual rebleed rate from $32 \%$ pretreatment to $1.1 \%$ within 2 years after RS, as well as low treatmentrelated persistent morbidity. Numerous contemporary studies adopting their strict planning, patient selection, and follow-up criteria have confirmed the reproducibility of these results (see review article in Nagy and Kemeny, $2015^{27}$ ), and our current results are in line with these earlier findings.

Specifically, highly conformal treatment planning, lesion definition strictly within the hemosiderin ring, the avoidance of associated developmental venous anomalies, the application of a lower prescription dose, and the treatment of lesions after resolution of the last hemorrhage led to about $5 \%$ mild, persistent AREs. ${ }^{27,28}$ The poor outcomes often cited by critics of RS are from an earlier era representing our collective learning curve with inaccurate target definition, unnecessarily high radiation dose, and confusion over the lesion's natural history. ${ }^{8,26,36}$ It was found in a recent study that the rate of AREs increased if CMs were treated with a prescription dose $>15$ Gy without the benefit of a reduction in posttreatment bleed rates. ${ }^{19}$ The effect of a further dose reduction, however, is not known as we did not find a correlation between outcome and dose within the range applied in the present study. Nevertheless, the current practice of the radiosurgical community is to treat these lesions with a lower prescription dose than was previously chosen based on AVM RS. ${ }^{28}$ Thus, critical voices regarding morbidity have been quieted recently.

In contrast to the initial cautious policy of treating lesions after at least two hemorrhages,${ }^{20}$ our stance has been more proactive from the beginning, treating CMs with no more than one prior bleed. This group represents twothirds of our patients, and our analysis of earlier results has reassured us to continue this practice. ${ }^{29}$ In agreement with our previous results, data in the present study indicated that the rates of both permanent AREs (7.2\%) and posttreatment bleed-related morbidity $(7.4 \%)$ were low and their effects were mild (AREs: all an increase of $1 \mathrm{mRS}$ score; posttreatment hemorrhage-related morbidity: $80 \%$ an increase of $1 \mathrm{mRS}$ score and $20 \%$ an increase of $2 \mathrm{mRS}$ scores), and treatment-specific mortality was $<1 \%$, all related to bleeds. Moreover, not only were the rate $(77.1 \%$ vs $48.8 \%$ ) and severity of pretreatment morbidity significantly higher in the multiple-bleed group, but the morbidity rate remained significantly lower in the single-bleed group even after RS (53.3\%). Thus, a second bleed carries a greater risk for persistent neurological deficits than that with early RS (Fig. 6 and Table 4). Similar results have been published by another group, ${ }^{23}$ and it appears that a proactive policy has recently been starting to gain wider acceptance. ${ }^{4}$

The most pertinent question currently is whether RS brings any benefit over the CM's natural history. Our understanding of natural history has significantly improved since 2010, when we presented our earlier results ${ }^{29}$ and the results of another large cohort from Pittsburgh were published. ${ }^{25}$ Opponents at that time argued with a virtual patient model obtained by a simulation based on available natural history data of heterogeneous quality; ${ }^{36}$ therefore, that debate was merely speculative. Since then, several good-quality natural history studies analyzing large patient populations have been published, and we felt it ap- 
propriate to reflect on them. In the present study we distinguished between two presentation forms: single-bleed and multiple-bleed groups. While in the single-bleed group the annual rebleed rate fell to $1.1 \%$ after a 2 -year temporary increase to $4.3 \%$, in the multiple-bleed group it fell from $20.7 \%$ pretreatment to $7.9 \%$ within the first 2 years after treatment and to $1.3 \%$ thereafter (Fig. 4 and Table 3). Importantly, the time course of a decay of the rebleed rates parallels the histological changes after RS found by a recent histopathological study. ${ }^{40}$ Kaplan-Meier analysis showed that the hemorrhage-free survival rate was $93.2 \%$ and $88.9 \%$ at 2 years, $91.7 \%$ and $88.9 \%$ at 5 years, and $86.4 \%$ and $75.1 \%$ at 20 years after RS in the single- and multiple-bleed groups, respectively (Fig. 5). Moreover, while we found a tendency for a spontaneous decline in annual bleed rates in the multiple-bleed group prior to treatment-in agreement with most previous studies - the rate remained as high as $11.5 \%$ even after 5 years, which is significantly higher than the long-term annual rebleed rate in the same cohort after RS (Fig. 3A). Comparing estimates of hemorrhage-free survival of the cohort before and after treatment (Fig. 3B), we found that the median hemorrhage-free survival was 42 months without treatment, and hemorrhage-free survival was estimated to be as high as $76 \%$ even at 20 years after treatment, which is a significant difference from the untreated course. In the context of recent natural history studies, our results compare favorably to those for an untreated course, suggesting that the reduction in the rebleed rate 2 years after RS is unlikely to be accounted for merely by "temporal clustering."

\section{Study Limitations}

Although our results strongly suggest the benefit of early radiosurgical intervention, we admit that the weakest points of our study are its retrospective design and lack of a matched control group, which are common to all of the published radiosurgical papers..$^{19,27}$ Critics of this method advocate a prospective randomized controlled trial to clarify the conflicting issues surrounding different management options for $\mathrm{CMs}^{33}$ As we pointed out above, we consider RS as a complementary rather than a competing intervention to resection, and we think that the ultimate question is whether to observe these lesions once they become symptomatic or to treat them with RS early after the first bleed. Thus, a prospective randomized trial or prospective case control study to compare conservative and early radiosurgical management after the first hemorrhage would be welcome, but the chances of conducting such trials are low. ${ }^{28}$ Even if such a study became a reality in the near future, it would take years to collect reliable long-term results. Therefore, as a next step forward, a more realistic, close goal would be to conduct a multicentric retrospective case control study inviting both investigators of published large observational cohorts ${ }^{16}$ and RS centers. ${ }^{27}$

\section{Conclusions}

Rebleed rates of deep-seated CMs are stabilized at around $1 \%$ following an initial 2-year latency interval after RS. This decrease was more dramatic than the gradual decay observed in untreated cases that had bled multiple times prior to RS. Moreover, estimated long-term hemorrhage-free survival of CMs with hemorrhagic presentation after RS is significantly higher than hemorrhage-free survival prior to treatment in the same group. Treatment-related permanent morbidity was rare and mild. Cumulative morbidity after RS performed after the first bleed (53\%) was significantly lower than pretreatment morbidity after multiple hemorrhages (77\%). Thus, the very low radiationinduced morbidity seems to be an acceptable compromise for the potential long-term protective effect of RS as compared to the morbidity of potential future hemorrhages. These observations reassured us in our practice of treating CMs with early RS, but comparative studies are needed to verify our approach.

\section{Acknowledgments}

We are grateful for all the staff of the National Centre for Stereotactic Radiosurgery for providing the highest standard patient care. Gábor Nagy holds a 2016 Ladislau and Melita Steiner Radiosurgery Fellowship provided by the Leksell Gamma Knife Society.

\section{References}

1. Abla AA, Lekovic GP, Garrett M, Wilson DA, Nakaji P, Bristol R, et al: Cavernous malformations of the brainstem presenting in childhood: surgical experience in 40 patients. Neurosurgery 67:1589-1599, 2010

2. Abla AA, Turner JD, Mitha AP, Lekovic G, Spetzler RF: Surgical approaches to brainstem cavernous malformations. Neurosurg Focus 29(3):E8, 2010

3. Aboukais R, Estrade L, Devos P, Blond S, Lejeune JP, Reyns N: Gamma Knife radiosurgery of brainstem cavernous malformations. Stereotact Funct Neurosurg 94:397-403, 2016

4. Akers A, Al-Shahi Salman R, Awad IA, Dahlem K, Flemming K, Hart B, et al: Synopsis of guidelines for the clinical management of cerebral cavernous malformations: consensus recommendations based on systematic literature review by the Angioma Alliance Scientific Advisory Board Clinical Experts Panel. Neurosurgery 80:665-680, 2017

5. Al-Shahi Salman R, Berg MJ, Morrison L, Awad IA: Hemorrhage from cavernous malformations of the brain: definition and reporting standards. Stroke 39:3222-3230, 2008

6. Al-Shahi Salman R, Hall JM, Horne MA, Moultrie F, Josephson CB, Bhattacharya JJ, et al: Untreated clinical course of cerebral cavernous malformations: a prospective, populationbased cohort study. Lancet Neurol 11:217-224, 2012

7. Barker FG II, Amin-Hanjani S, Butler WE, Lyons S, Ojemann RG, Chapman PH, et al: Temporal clustering of hemorrhages from untreated cavernous malformations of the central nervous system. Neurosurgery 49:15-25, 2001

8. Bertalanffy H, Gerganov VM: Microsurgical or radiosurgical management of intracranial cavernomas. Acta Neurochir Suppl 116:103-106, 2013

9. Bradac O, Majovsky M, de Lacy P, Benes V: Surgery of brainstem cavernous malformations. Acta Neurochir (Wien) 155:2079-2083, 2013

10. Fritschi JA, Reulen HJ, Spetzler RF, Zabramski JM: Cavernous malformations of the brain stem. A review of 139 cases. Acta Neurochir (Wien) 130:35-46, 1994

11. Gross BA, Batjer HH, Awad IA, Bendok BR: Cavernous malformations of the basal ganglia and thalamus. Neurosurgery 65:7-19, 2009

12. Gross BA, Batjer HH, Awad IA, Bendok BR, Du R: Brainstem cavernous malformations: 1390 surgical cases from the literature. World Neurosurg 80:89-93, 2013

13. Gross BA, Du R: Hemorrhage from cerebral cavernous 
malformations: a systematic pooled analysis. J Neurosurg 126:1079-1087, 2017

14. Hamilton T, Lunsford LD: Worldwide variance in the potential utilization of Gamma Knife radiosurgery. J Neurosurg 125 (Suppl 1):160-165, 2016

15. Hasegawa T, McInerney J, Kondziolka D, Lee JY, Flickinger JC, Lunsford LD: Long-term results after stereotactic radiosurgery for patients with cavernous malformations. Neurosurgery 50:1190-1198, 2002

16. Horne MA, Flemming KD, Su IC, Stapf C, Jeon JP, Li D, et al: Clinical course of untreated cerebral cavernous malformations: a meta-analysis of individual patient data. Lancet Neurol 15:166-173, 2016

17. Jeon JS, Kim JE, Chung YS, Oh S, Ahn JH, Cho WS, et al: A risk factor analysis of prospective symptomatic haemorrhage in adult patients with cerebral cavernous malformation. J Neurol Neurosurg Psychiatry 85:1366-1370, 2014

18. Kida Y: Radiosurgery for cavernous malformations in basal ganglia, thalamus and brainstem. Prog Neurol Surg 22:3137, 2009

19. Kida Y, Hasegawa T, Iwai Y, Shuto T, Satoh M, Kondoh T, et al: Radiosurgery for symptomatic cavernous malformations: A multi-institutional retrospective study in Japan. Surg Neurol Int 6 (Suppl 5):S249-S257, 2015

20. Kondziolka D, Lunsford LD, Coffey RJ, Bissonette DJ, Flickinger JC: Stereotactic radiosurgery of angiographically occult vascular malformations: indications and preliminary experience. Neurosurgery 27:892-900, 1990

21. Kondziolka D, Lunsford LD, Flickinger JC, Kestle JR: Reduction of hemorrhage risk after stereotactic radiosurgery for cavernous malformations. J Neurosurg 83:825-831, 1995

22. Kondziolka D, Lunsford LD, Kestle JR: The natural history of cerebral cavernous malformations. J Neurosurg 83:820824,1995

23. Lee SH, Choi HJ, Shin HS, Choi SK, Oh IH, Lim YJ: Gamma Knife radiosurgery for brainstem cavernous malformations: should a patient wait for the rebleed? Acta Neurochir (Wien) 156:1937-1946, 2014

24. Li D, Hao SY, Jia GJ, Wu Z, Zhang LW, Zhang JT: Hemorrhage risks and functional outcomes of untreated brainstem cavernous malformations. J Neurosurg 121:32-41, 2014

25. Lunsford LD, Khan AA, Niranjan A, Kano H, Flickinger JC, Kondziolka D: Stereotactic radiosurgery for symptomatic solitary cerebral cavernous malformations considered high risk for resection. J Neurosurg 113:23-29, 2010

26. Mitchell P, Hodgson TJ, Seaman S, Kemeny AA, Forster DM: Stereotactic radiosurgery and the risk of haemorrhage from cavernous malformations. Br J Neurosurg 14:96-100, 2000

27. Nagy G, Kemeny AA: Radiosurgery for cerebral cavernomas. J Neurosurg Sci 59:295-306, 2015

28. Nagy G, Kemeny AA: Stereotactic radiosurgery of intracranial cavernous malformations. Neurosurg Clin N Am 24:575-589, 2013

29. Nagy G, Razak A, Rowe JG, Hodgson TJ, Coley SC, Radatz $\mathrm{MW}$, et al: Stereotactic radiosurgery for deep-seated cavernous malformations: a move toward more active, early intervention. Clinical article. J Neurosurg 113:691-699, 2010

30. Nagy G, Stokes SS, Erőss LG, Bhattacharyya D, Yianni J, Rowe JG, et al: Contemporary radiosurgery of cerebral cavernous malformations: Part 2. Treatment outcome for hemispheric lesions. J Neurosurg [epub ahead of print July 27 , 2018; DOI: 10.3171/2018.2.JNS171267]

31. Nagy G, Yianni J, Bhattacharyya D, Rowe JG, Kemeny AA, Radatz MWR: Repeat radiosurgical treatment after cavernous malformation radiosurgery. World Neurosurgery [epub ahead of print], 2018

32. Niranjan A, Lunsford LD: Stereotactic radiosurgery guidelines for the management of patients with intracranial cavernous malformations. Prog Neurol Surg 27:166-175, 2013
33. Poorthuis M, Samarasekera N, Kontoh K, Stuart I, Cope B, Kitchen N, et al: Comparative studies of the diagnosis and treatment of cerebral cavernous malformations in adults: systematic review. Acta Neurochir (Wien) 155:643-649, 2013

34. Poorthuis MH, Klijn CJ, Algra A, Rinkel GJ, Al-Shahi Salman R: Treatment of cerebral cavernous malformations: a systematic review and meta-regression analysis. J Neurol Neurosurg Psychiatry 85:1319-1323, 2014

35. Porter RW, Detwiler PW, Spetzler RF, Lawton MT, Baskin JJ, Derksen PT, et al: Cavernous malformations of the brainstem: experience with 100 patients. J Neurosurg 90:50-58, 1999

36. Steiner L, Karlsson B, Yen CP, Torner JC, Lindquist C, Schlesinger D: Radiosurgery in cavernous malformations: anatomy of a controversy. J Neurosurg 113:16-22, 2010

37. Szeifert GT, Levivier M, Lorenzoni J, Nyáry I, Major O, Kemeny AA: Morphological observations in brain arteriovenous malformations after gamma knife radiosurgery. Prog Neurol Surg 27:119-129, 2013

38. Taslimi S, Modabbernia A, Amin-Hanjani S, Barker FG II, Macdonald RL: Natural history of cavernous malformation: systematic review and meta-analysis of 25 studies. Neurology 86:1984-1991, 2016

39. Tian KB, Zheng JJ, Ma JP, Hao SY, Wang L, Zhang LW, et al: Clinical course of untreated thalamic cavernous malformations: hemorrhage risk and neurological outcomes. J Neurosurg 127:480-491, 2017

40. Tu J, Stoodley MA, Morgan MK, Storer KP, Smee R: Different responses of cavernous malformations and arteriovenous malformations to radiosurgery. J Clin Neurosci 16:945-949, 2009

41. Tung H, Giannotta SL, Chandrasoma PT, Zee CS: Recurrent intraparenchymal hemorrhages from angiographically occult vascular malformations. J Neurosurg 73:174-180, 1990

42. Ulrich NH, Kockro RA, Bellut D, Amaxopoulou C, Bozinov $\mathrm{O}$, Burkhardt JK, et al: Brainstem cavernoma surgery with the support of pre- and postoperative diffusion tensor imaging: initial experiences and clinical course of 23 patients. Neurosurg Rev 37:481-492, 2014

43. van Swieten JC, Koudstaal PJ, Visser MC, Schouten HJ, van Gijn J: Interobserver agreement for the assessment of handicap in stroke patients. Stroke 19:604-607, 1988

\section{Disclosures}

The authors report no conflict of interest concerning the materials or methods used in this study or the findings specified in this paper.

\section{Author Contributions}

Conception and design: Nagy, Kemeny. Acquisition of data: Burkitt, Stokes, Kemeny. Analysis and interpretation of data: Nagy. Drafting the article: Nagy. Critically revising the article: Radatz, Bhattacharyya, Yianni, Rowe, Kemeny. Reviewed submitted version of manuscript: Radatz, Bhattacharyya, Yianni, Rowe, Kemeny. Statistical analysis: Nagy. Administrative/technical/ material support: Burkitt. Study supervision: Radatz.

\section{Supplemental Information \\ Companion Papers}

Nagy G, Stokes SS, Eróss LG, Bhattacharyya D, Yianni J, Rowe JG, et al: Contemporary radiosurgery of cerebral cavernous malformations: Part 2. Treatment outcome for hemispheric lesions. DOI: $10.3171 / 2018.2 . J N S 171267$.

\section{Correspondence}

Matthias W. R. Radatz: The National Centre for Stereotactic Radiosurgery, Royal Hallamshire Hospital, Sheffield, United Kingdom.radatz@blueyonder.co.uk. 